\title{
La narrativa pública en salud: análisis de grandes reportajes sobre el ébola
}

\author{
Margoth Mena-Young ${ }^{1}$ \\ Centro de Investigación en Comunicación, Universidad de Costa Rica, San José, Costa Rica
}

Resumen: Este estudio presenta un análisis de las narrativas de grandes reportajes publicados sobre la epidemia del ébola en tres países iberoamericanos, recolectados en el primer semestre del 2015, en el marco del primer aniversario del brote de la enfermedad en África. Los textos son de los diarios El País de España, El Universal de México y La Nación de Costa Rica. Se trabajó con todos los reportajes sobre el ébola que tuvieran más de mil palabras de extensión, y se analizaron las estrategias narrativas de los textos mediante el estudio cualitativo de sus estructuras y recursos literarios. Entre los resultados obtenidos, hay diferencias en el foco de las historias: las víctimas, la comprensión de la propia enfermedad, y el papel de la ciencia. Hay un esfuerzo del periódico español por humanizar a las víctimas, aunque las mujeres no tuvieron voz o representación en ninguno de los tres diarios.

Palabras clave: Periodismo de salud; Comunicación de la salud; Comunicación de la ciencia.

Título: A narrativa pública em saúde: análise de grandes reportagens sobre o ebola

Resumo: Este estudo apresenta uma análise das narrativas de grandes reportagens publicadas sobre a epidemia de Ebola em três países ibero-americanos, coletados no primeiro semestre de 2015, por ocasião do primeiro aniversário do surto da doença na África. Os textos são dos jornais El País de España, El Universal de México e La Nación de Costa Rica. Trabalhamos com todas as reportagens sobre o ebola cuja extensão ultrapassou mil palavras e analisamos as estratégias narrativas dos textos mediante o estudo qualitativo das suas estruturas e recursos literários. Entre os resultados obtidos, existem diferenças no foco das histórias: as vítimas, a compreensão da própria doença e o papel da ciência. Há um esforço do jornal espanhol em humanizar as vítimas, embora as mulheres não tenham tido voz ou representação em nenhum dos três jornais.

Palavras-chave: Jornalismo de saúde; Comunicação em saúde; Comunicação científica.

Title: The public narrative in health: analysis of large reportages on Ebola

Abstract: This study presents an analysis of the narratives of the large reportages published on the Ebola epidemic in three Latin American countries, collected in the first half of 2015, as part of the first anniversary of the disease outbreak in Africa. The texts are from the newspapers El País from España, El Universal from México and La Nación from Costa Rica. This research worked with all the reportages on Ebola of more than a thousand words and analyzed the narrative strategies of the texts using a study of their structures and literary resources. About the results, there are differences in the focus of the stories: the victims,

\footnotetext{
${ }^{1}$ Doctora en Comunicación por la Universidad de Málaga, España, Investigadora en el Centro de Investigación en Comunicación de la Universidad de Costa Rica, en la línea de comunicación pública de la ciência. Orcid: https://orcid.org/0000-0002-9495-9081
}

E-mail: margoth.mena@ucr.ac.cr 
the understanding of the disease itself, and the role of science. There is an effort by the newspaper from Spain to humanize the victims, although the women had no voice or representation in any of the three newspapers.

Keywords: Health journalism; Health communication; Science communication.

\section{Introducción y antecedentes}

El mayor brote de ébola en la historia surgió en marzo del 2014 en África occidental y un año después, en el mismo mes, los diarios a nivel mundial aprovecharon la fecha para hacer una reseña de lo acontecido hasta ese momento y de los esfuerzos implementados. La Organización Mundial de la Salud (OMS) también brindó informes periódicos, actualizando estadísticas y detallando los esfuerzos de contención implementados en colaboración con Gobiernos y otras organizaciones. El mundo estaba preocupado: la epidemia se podía extender causando una pandemia y existía incertidumbre sobre si los diferentes países estaban preparados para afrontarla. En octubre del 2014, el diario español El Mundo publicó una noticia donde Thomas Frieden, responsable de la lucha contra el ébola en EEUU, declaró que si la enfermedad no se controlaba pronto, se convertiría "en el nuevo sida". (PARDO, 2014, párr. 1)

La cobertura en extenso de esta epidemia es de interés para reflexionar sobre el tratamiento de las historias y el manejo de la información pública en un contexto digital global: la movilidad de los seres humanos hace que las enfermedades contagiosas que se piensan lejanas pasen a ser próximas, y la cobertura de la prensa debe buscar la comprensión y la prevención, sin omisiones o alarmismo injustificado.

El interés en analizar el contenido sobre salud en los medios de comunicación y otras narrativas se puede observar en estudios como el de Alcibar (2008) sobre clonación humana; el de Dixon y Clarke (2013) sobre la relación entre vacuna y autismo; el de Evensen y Clarke (2012) sobre enfermedades infectocontagiosas; el de salud pública de Braun (2007); o el de salud mental de Allepuz-Faus, Caro, Rojo-Serrano y Yera-Sabater (2014) El abordaje de estos estudios no se realiza solamente desde el campo de la comunicación o la linguística, sino también desde los propios campos de las ciencias médicas. Un ejemplo es el desarrollo de una línea en tratamientos médicos, como la representación de las vacunas en la prensa (DIXON y CLARKE, 2013; REN, PETERS, ALLGAIER y LO, 2014), el escáner cerebral (RACINE, BAR-ILAN e ILLES, 2006), las células madre (VICSEK, 2011); la biomedicina (NISBET y MARKOWITZ, 2014) y la medicina genómica (ZHAO et al., 2014).

De manera más cercana al estudio que se presenta, la narrativa y análisis de contenido sobre información pública de enfermedades humanas tiene múltiples acercamientos: artículos sobre cáncer (BRECHMAN, LEE y CAPPELLA, 2009; COKKINIDES, KIRKLAND, ANDREWS, SULLIVAN y LICHTENFELD, 2012; KREUTER et al., 2007); sobre el SIDA (D'ANGELO, POLLOCK, KIERNICKI y SHAW, 2013), enfermedades infectocontagiosas (EVENSEN 
y CLARKE, 2012); la gripe aviar (UNGAR, 2008); o el alcohol fetal (CONNOLLY-AHERN y BROADWAY, 2008). Todos ellos son preocupaciones generales a nivel mundial y su cantidad demuestra coherencia con la presencia permanente de temas de ciencias de la salud en periódicos alrededor del mundo.

Sumado a lo anterior, los estudios de percepción pública de la ciencia que se realizan en varios países iberoamericanos muestran también la preferencia que las audiencias tienen por la información en salud. Un ejemplo de lo anterior es el caso de España, donde cada dos años desde el 2002 realizan su estudio nacional. En los resultados del 2018, la FECYT encontró que el interés en medicina y salud (37.9\%), continúa de número uno entre la población, seguido de trabajo y empleo (31.9\%), educación (28.8\%), deportes $(24.4 \%)$ y política (22.7\%).

Los medios de prensa tienen entonces una gran responsabilidad, pues junto a las redes sociales, son el primer canal para informar a la población sobre salud. Con su presencia en internet, los periodistas afrontan las nuevas funciones de investigación y difusión de noticias e historias: la presión de la instantaneidad y el clickbait los hace contar con menos tiempo para antecedentes, contexto o reflexión en sus escritos.

Ya lo retrataba desde el 2011 Ignacio Ramonet (2011) cuando explicaba que,

El periodismo no consiste sólo en proporcionar estadísticas, cifras y hechos, sino en elaborar y construir, a partir de esa materia prima, un relato rico en todos los ingredientes -léxicos, retóricos, dramáticos- característicos de las grandes historias de siempre. A veces olvidamos que el periodismo pertenece a la familia del arte literario. (RAMONET, 2011, p. 149)

Los periodistas entonces, necesitan tiempo para producir un contenido de calidad, innovador y de impacto, y es por eso que este trabajo se enfoca en los grandes reportajes, donde existe el espacio para contar una historia llena de detalles, texturas y diversidades. Ramón Reig (2015) lo menciona al sugerir que el periodista debe tener el tiempo para "adentrarse en comunidades y situaciones ajenas, con el propósito de experimentar vivencias y perfiles e interactuar con el entorno." (p. 259) Ese tiempo es más difícil en redacciones integradas, siendo periodista multifuente o trabajando en un medio de comunicación con problemas financieros.

Para trabajar com el género periodístico de reportaje, se seleccionó la conceptualización de Echevarría (2011) que lo describe como el texto periodístico fruto de una investigación profunda mediante la cual el periodista describe, explica, informa, relata, analiza, compara e interpreta un hecho (p. 28). Este autor considera esenciales los antecedentes, contextualización, análisis, reacciones e interpretaciones en este género, así como el uso de múltiples fuentes, diversas estructuras textuales y amplia libertad de recursos expresivos, lingüísticos y formales. 


\section{Métodos}

La investigación realizada fue de tipo cualitativa, mediante análisis discursivo de grandes reportajes sobre ebola de 1000 palabras o más, publicados durante el primer semestre del 2015 por El País de España, El Universal de México y La Nación de Costa Rica. Los periódicos fueron selecionados por ser de cobertura nacional, con versión tanto impresa como digital disponible, periodicidad diaria, cobertura nacional, y liderazgo en tráfico en su web (ALEXA, 2018) y redes sociales.

El objetivo de la investigación fue analizar la narrativa de los grandes reportajes sobre ebola en los tres diarios mencionados mediante las siguientes etapas: a- analizar el desarrollo narrativo de los textos; b- identificar la estrutura narrativa; $y$, c- identificar los recursos literarios utilizados. Las categorías de análisis se muestran en la Tabla 1.

Tabla 1 - Categorías de análisis utilizadas para analizar narrativas periodísticas

\begin{tabular}{lll}
\hline Estructura narrativa & Análisis narrativo & Recursos literarios \\
\hline - Características & - Situación inicial & - Sorpresa \\
generales & - Nudo o complicación & - Humor \\
- Protagonistas & - Acción o evaluación & - Metáforas \\
- Funciones & - Resolución & - Emociones \\
\hline
\end{tabular}

Fuente: elaboración propia (2019)

El estudio toma como base la forma de analizar narrativas de autores como Negrete (2012) que, siguiendo a Propp, recomienda tres espacios para analizar las narrativas en la comunicación de la ciencia: a- las estructuras narrativas: personajes, funciones de estos y esferas de acción; b- el lenguaje figurativo: rima, sorpresa, humor, metáfora, imaginería y emociones; y c- los tipos de narrativas: mitos, parábolas, cuentos, ciencia ficción. También se consideró el trabajo de Nerlich, Koteyko y Brown (2010), en el que analizaron las metáforas, palabras, estrategias, marcos y narrativas en la transmisión de la información sobre cambio climático. Fue importante el aporte de Berruecos (2005), que aporta cinco proposiciones narrativas de análisis: situación inicial; nudo o complicación; acción o evaluación; resolución; y situación final; junto al trabajo de Palau (2014), del cual se incluyó el análisis de actores sociales, mediante citas directas o indirectas.

Para analizar la respuesta de la prensa ante esta epidemia, en el marco de un interés específico por los grandes formatos, se encontró que varias revistas científicas publicaron investigaciones sobre la enfermedad y su mutación en el período de aniversario, que fueron la fuente para los grandes reportajes que publicaron los diarios en estudio en el primer semestre del 2015. Ninguno de los artículos utilizó el mismo tema ni estilo, pero tuvieron en 
común la presencia de la OMS como fuente de información mediante un vocero experto, un reporte en su web o un comunicado de prensa. Estos datos confirman que la OMS fue proactiva y generó información de interés que hizo llegar a agencias de prensa y a medios de comunicación. La tabla 2 muestra los reportajes con los que se trabajó.

Tabla 2 - Grandes reportajes sobre ébola en los diarios analizados

\begin{tabular}{|c|c|c|c|c|}
\hline Diario & Día & Género periodístico & Título & Fuentes \\
\hline El País & $\begin{array}{l}22 \text { de } \\
\text { marzo }\end{array}$ & $\begin{array}{l}\text { Interpretativo } \\
\text { Retrospectivo }\end{array}$ & El ébola se enroca & $\begin{array}{l}\text { New England Journal of } \\
\text { Medicine; Médicos Sin } \\
\text { Fronteras; OMS. }\end{array}$ \\
\hline El Universal & $\begin{array}{l}11 \text { de } \\
\text { enero }\end{array}$ & Informativo & $\begin{array}{l}\text { Enfermedades sin } \\
\text { cura (un apartado al } \\
\text { ébola) }\end{array}$ & $\begin{array}{l}\text { Sociedad Española de } \\
\text { Médicos de Atención } \\
\text { Primaria; OMS. }\end{array}$ \\
\hline La Nación & $\begin{array}{l}31 \text { de } \\
\text { marzo }\end{array}$ & $\begin{array}{l}\text { Informativo, noticia } \\
\text { múltiple }\end{array}$ & $\begin{array}{l}\text { Título principal: Virus } \\
\text { del Ébola muta más } \\
\text { lento de lo } \\
\text { sospechado } \\
\text { Título secundario: } \\
\text { Gravedad del mal } \\
\text { varía según edad del } \\
\text { paciente. }\end{array}$ & $\begin{array}{l}\text { Reporte OMS; Science; } \\
\text { Comunicado OMS; } \\
\text { New England Journal of } \\
\text { Medicine; virólogo } \\
\text { David Loría; Jean Marie } \\
\text { Dangou, representante } \\
\text { de la OMS. }\end{array}$ \\
\hline
\end{tabular}

Fuente: elaboración propia a partir de reportajes del I semestre 2015

\section{Resultados}

\section{Estructura narrativa}

Como se observa en la tabla 2, el tratamiento en los titulares no fue unánime: dos fueron negativos y el tercero, ambiguo, que fue el caso de La Nación, donde un lector poco asiduo a temas de salud no podrá saber si es algo positivo o no que el ébola mute lento. Al leer todo el reportaje se evidencia que la noticia es positiva, mientras que los otros dos diarios se mantienen negativos luego de terminar la lectura completa, con mensajes clave como "no existen tratamientos curativos" o "continúan los contagios".

Sobre las fuentes que sustentaron los reportajes, el diario mexicano no incluye ninguna fuente nacional experta en sus artículos, y tampoco El País, aunque este último sí tomó un caso de un religioso español, quien al ser repatriado se convirtió en la primera víctima del ébola en Europa. La Nación incluye mayor cantidad de fuentes y entre ellas las declaraciones de un virólogo de ese país, aunque no eran actuales, sino un refrito de una publicación antigua del diario.

En el caso del periódico español, este fue el único que optó por historias personales 
de los afectados en África y España para contar los sucesos, narrando al lector lo acontecido desde el inicio de la epidemia. Su género fue interpretativo y cae dentro del reportaje retrospectivo por lo que fue redactado en pasado en su mayoría, y solamente el primero y el último párrafo se escribieron en presente. El título es negativo al igual que los usados por El Universal y uno de los de La Nación, que utilizó el formato de noticia múltiple. El título principal del periódico costarricense es más bien neutro, pues el lector promedio no puede anticipar si la mutación lenta del virus es un descubrimiento bueno o no.

El tema de La Nación se centra en un estudio científico que compara la composición genética del virus del 2013-2015, con muestras de la década anterior. Los resultados comprobaron que la mutación es poca y el comportamiento del virus se mantiene, lo cual hace posible trabajar en una vacuna. Esta proyección del beneficio que puede traer el hallazgo, es lo que causa la presencia de tantos verbos en modo condicional en este texto. Este diario también añade otra nota (formato de noticia múltiple mencionado) con un estudio adicional publicado en una revista científica, que analiza las diferencias que causa el virus en aspectos como contagios, síntomas y mortalidad, con respecto a la edad del paciente.

Los tres diarios tienen un enfoque internacional en sus reportajes, pero su relato es diferente. La Nación publica un texto informativo con base en un descubrimiento científico sobre la mutación muy lenta del virus y la posibilidad de una vacuna. El País hace un reportaje retrospectivo en conmemoración del primer aniversario de la epidemia de esta década en África. Por último, El Universal brinda solamente datos generales de la enfermedad, sus síntomas y transmisión, ya que dedica a esta una parte de un texto más grande.

De los tres grandes reportajes publicados sobre ebola en estos médios en la primera mitad del 2015, solo el reportaje de La Nación de Costa Rica contenía tanto antecedentes como contexto actual; El País, por el contrario, al ser un texto interpretativo de tipo retrospectivo, contenía gran cantidad de historia de la epidemia, pero solamente un párrafo en tiempo presente. La Nación además fue el único en brindar una posición prospectiva sobre la posibilidad de obtener un vacuna para el mal.

Los tres reportajes tienen autoría distinta. Mientras que La Nación hizo su producción con una periodista nacional de planta, El Universal publicó un texto de la agencia EFE, y EI País obtuvo un reportaje de un periodista extranjero en modalidad freelance, radicado en África occidental. La proximidad de este autor podría haber incidido en un reportaje actual pero fue retrospectivo, con un texto más interpretativo, lleno de emociones y recursos literarios.

Las fuentes preferidas fueron organismos internacionales y las organizaciones sin fines de lucro, sin menciones a empresas ni a entes de Gobierno central. A diferencia de la mayoría de reportajes en ciencia y salud, tanto voceros como voceras tuvieron poco aporte, ya que los textos fueron construidos a partir de testimonios, publicaciones, reportes 0 
comunicados. Solamente La Nación incluyó dos voceros expertos de sexo masculino; El País incluyó casos y declaraciones de enfermos; y El Universal solo reportes organizacionales.

En dos de los tres textos estuvieron representadas las revistas científicas y por ellos también estuvo presente el inglés en la misma cantidad. Las revistas citadas son de países desarrollados y considerados potencias políticas y económicas mundiales.

A pesar de tener consecuencias a nivel mundial, los textos no incluyen controversias ni mención alguna de cooperación entre países y tampoco dejan detalle sobre las necesidades económicas o de otra índole que se necesitan para erradicar o controlar el virus. Únicamente El País aborda los obstáculos para ese control al mencionar los entierros no seguros en los países con epidemia, la movilidad de las personas y la "desconfianza de la población, que muestra resistencia a los ensayos de nuevos tratamientos", en palabras del mismo redactor.

La tabla 3 ilustra las funciones y acciones presentes de los protagonistas en la narrativa pública sobre ébola. En El País, los protagonistas principales son enfermos, la mayoría de ellos muertos a consecuencias del virus. El texto va narrando la forma en que se contagiaron y esa secuencia es coherente con los focos de avance de la epidemia. Las declaraciones de estos personajes (testigos directos y actores sociales) reflejan el sufrimiento por el ébola y uno de ellos, que sobrevive, narra el rechazo de su comunidad.

Una de las principales diferencias respecto a la comunicación de epidemias anteriores es que, en esta ocasión, los propios afectados se convirtieron en fuente de información con tanto protagonismo como las fuentes oficiales (FUNDACIÓ VILA CASAS, 2014, p. 41)

El País de España incluyó esta diferencia en su redacción, y esta característica apoya un tipo de construcción de identidade llamado corresidencia (SOLÁ, 2013), categoría en la que se reflejan las interacciones que los civiles y los grupos organizados mantienen entre ellos, con el espacio público o en su ambiente natural (pp. 35-41).

En El País de España, la tendencia de la cobertura de prensa fue darle voz a los afectados y esto se refleja también en los reportajes. Aun así, se debe añadir que las declaraciones entrecomilladas todas son de hombres, a pesar de que entre el $55 \%$ y el $60 \%$ de las muertes por ébola en Guinea y Sierra Leona en 2014 fueron mujeres, según menciona The Washington Post en 2014 (HOGAN, 14 de agosto 2014).

Las mujeres se ocupan de proveer los cuidados a sus familiares, a los enfermos ingresados en los centros de salud, y son las principales responsables de realizar las prácticas funerarias propias de las zonas afectadas, que incluyen el lavado de los cadáveres. (MENÉNDEZ, 2015)

Las historias repiten lo que pasa en la realidad social en este tema, que tiene rostro 
de hombres, de niños, de religiosos, cooperantes y otros, pero no de mujer: ellas mueren sin tener voz. El personal sanitario y los religiosos tienen la misma acción que la mujer: cuidar enfermos. Este tipo de labor trae como consecuencia el contagio y la muerte, pero solo hay un reconocimiento público en el caso de los doctores y de los religiosos, con nombres, fotografías y coberturas de prensa. Lo anterior se observa en uno de los reportajes del diario español, en el que se menciona a un doctor como "héroe" en su localidad.

Tabla 3 - Estructura narrativa de los reportajes sobre ébola en los diarios analizados

\begin{tabular}{|c|c|c|c|}
\hline Diario & Protagonistas & Funciones & Acciones \\
\hline \multirow{8}{*}{ El País } & - El ébola & $\begin{array}{l}\text { - Epidemia } \\
\text { - Responsable de las } \\
\text { misteriosas } \\
\text { muertes }\end{array}$ & $\begin{array}{l}\text { - Ha cobrado más de } 10.000 \text { muertos } \\
\text { - Se colaba en una gran ciudad y ha dado el } \\
\text { salto a otros dos países } \\
\text { - Se ha ralentizado, pero sigue activa }\end{array}$ \\
\hline & $\begin{array}{l}\text { - Mamadou Cissé } \\
\text { (nombre ficticio), } \\
\text { Guinea }\end{array}$ & $\begin{array}{l}\text { - Enfermo } \\
\text { sobreviviente } \\
\text { - Contagiado } \\
\end{array}$ & $\begin{array}{l}\text { - Contagiado por su hermano } \\
\text { - Nos rechazan, nos señalan con el dedo }\end{array}$ \\
\hline & $\begin{array}{l}\text { - Doctor Umar Khan, } \\
\text { Sierra Leona }\end{array}$ & $\begin{array}{l}\text { - Doctor muy } \\
\text { meticuloso } \\
\text { - Atendió pacientes } \\
\text { con ébola } \\
\text { - Murió de ébola } \\
\text { - Héroe }\end{array}$ & $\begin{array}{l}\text { - Laboró con personal escaso y en turnos } \\
\text { dobles }\end{array}$ \\
\hline & $\begin{array}{l}\text { - Religioso español } \\
\text { Miguel Pajares }\end{array}$ & $\begin{array}{l}\text { - Enfermo } \\
\text { - Primera víctima } \\
\text { que falleció en } \\
\text { Europa }\end{array}$ & $\begin{array}{l}\text { - Atendió a otro religioso que murió } \\
\text { - Envío una petición de ayuda } \\
\text { - Murió luego de ser repatriado }\end{array}$ \\
\hline & $\begin{array}{l}\text { - Patrick Sawyer, } \\
\text { asesor del Gobierno } \\
\text { liberiano }\end{array}$ & - Enfermo & - Introdujo el virus en Nigeria \\
\hline & - Autoridades & - Detener contagio & $\begin{array}{l}\text { - Anunciaban al mundo los casos } \\
\text { - Cerraron hospitales con riesgo } \\
\text { - Repatriación de cooperantes }\end{array}$ \\
\hline & - Familias & - Contagiados & - Cuidar enfermos \\
\hline & $\begin{array}{l}\text { - Personal sanitario. } \\
\text { - Auxiliar de } \\
\text { enfermería Teresa } \\
\text { Romero }\end{array}$ & $\begin{array}{l}\text { - Contagiados } \\
\text { - Primer caso de } \\
\text { transmisión fuera } \\
\text { de África }\end{array}$ & - Cuidar enfermos \\
\hline \multirow[t]{2}{*}{ El Universal } & - Ébola & $\begin{array}{l}\text { - Enfermedad } \\
\text { incurable } \\
\text { - Enfermedad vírica } \\
\text { aguda grave } \\
\text { - Enfermedades } \\
\text { zoonóticas (que se } \\
\text { transmiten de } \\
\text { animales a } \\
\text { humanos) }\end{array}$ & $\begin{array}{l}\text { - Actual brote: el más grande de la historia } \\
\text { - Infección: por contacto directo con } \\
\text { sangre, secreciones u otros líquidos } \\
\text { corporales de personas infectadas } \\
\text { - Aparición súbita de fiebre, debilidad } \\
\text { intensa y dolor en los músculos, la cabeza } \\
\text { y la garganta, seguido de vómitos, } \\
\text { diarrea, erupciones cutáneas, disfunción } \\
\text { renal y hepática y, en algunos casos, } \\
\text { hemorragias internas y externas } \\
\end{array}$ \\
\hline & - Enfermos & -- & $\begin{array}{l}\text { - Suelen estar deshidratados y necesitan } \\
\text { rehidratación por vía intravenosa u oral } \\
\text { con soluciones que contengan }\end{array}$ \\
\hline
\end{tabular}




\begin{tabular}{|c|c|c|c|}
\hline Diario & Protagonistas & Funciones & Acciones \\
\hline & & & electrolitos \\
\hline & - Especialistas & $\begin{array}{l}\text { - Estudian el virus y } \\
\text { la enfermedad }\end{array}$ & $\begin{array}{l}\text { - Describen la enfermedad } \\
\text { - Publican } \\
\text { - Evalúan nuevos tratamientos } \\
\text { farmacológicos }\end{array}$ \\
\hline \multirow{3}{*}{ La Nación } & - El ébola & $\begin{array}{l}\text { - Enfermedad } \\
\text { - Patógeno } \\
\text { - Causante de } \\
\text { epidemia } \\
\end{array}$ & $\begin{array}{l}\text { - Estabilidad genética } \\
\text { - Muta más lento } \\
\text { - Comportamiento se mantiene en el } \\
\text { tiempo }\end{array}$ \\
\hline & - Científicos & $\begin{array}{l}\text { - Analizar la } \\
\text { genética } \\
\text { - Crear una } \\
\text { herramienta } \\
\text { contra el ébola } \\
\text { - Asegurar que la } \\
\text { vacuna tenga } \\
\text { pocos efectos } \\
\text { secundarios }\end{array}$ & $\begin{array}{l}\text { - Hacen pruebas en humanos } \\
\text { - Pueden desarrollar vacuna preventiva } \\
\text { - Publicaron en las revistas Science y New } \\
\text { England Journal of Medicine } \\
\text { - Compararon brotes entre décadas }\end{array}$ \\
\hline & $\begin{array}{l}\text { - Estudios y ensayos } \\
\text { clínicos }\end{array}$ & $\begin{array}{l}\text { - Determinar la } \\
\text { seguridad y } \\
\text { eficacia de una } \\
\text { inyección }\end{array}$ & $\begin{array}{l}\text { - "Retratan" la enfermedad } \\
\text { - Mayor contagio en + } 16 \text { años. } \\
\text { - El tiempo de enfermedad es más extenso } \\
\text { en adultos } \\
\text { - Importancia de incluir a los niños en los } \\
\text { seguimientos médicos }\end{array}$ \\
\hline
\end{tabular}

Fuente: elaboración propia a partir de reportajes del I semestre 2015

Las autoridades, un protagonista bastante disminuido en el reportaje de El País, son incluidas de forma anónima, como un colectivo, y en labores operativas de atención de la emergencia, alejadas de emociones y de enfermos o muertes.

Aunque el ébola es también protagonista en este diario, tiene poco texto que directamente se refiera al virus en cuanto a sus funciones y acciones: estas quedan claras mediante los actos, emociones y consecuencias en las personas. El texto contiene narrativa donde se personifica al ébola, por ejemplo "saltó a otros dos países", lo que lo hace reconocible como ente, y le da al lector un sentido de impotencia hacia sus "capacidades" de viajar.

Cabe anotar que los protagonistas tienen poca descripción en cuanto a sus características físicas o emocionales y sus actos son más importantes (inicio, complicación y final) en estos relatos de El País.

En el texto de El Universal, el protagonista es el ébola en tanto virus y enfermedad. La alerta pública tiene su mensaje en "incurable", pero no profundizan más, pues el tema es parte de un reportaje más grande que dedica espacio a otras enfermedades en la misma categoría. Tanto los enfermos como los especialistas son colectivos anónimos, pero los segundos tienen voz dentro de la narrativa y los enfermos pierden su rostro y su contexto.

La Nación, por su parte, también coloca al ébola como protagonista clave y, al igual 
que El Universal, tampoco usa lenguaje figurativo, como sí lo hace El País. El diario costarricense fue el único en utilizar tecnolectos en su elaboración, por ejemplo al utiliza la palabra "patógeno" para referirse a la enfermedad, o cuando explican el descubrimiento de la lentitud en la mutación del virus de esta manera:

Tras analizar la genética de virus aislados en diferentes comunidades donde la enfermedad está presente, entre 2013 y 2015, y al compararlos con los de brotes anteriores en la década anterior, las diferencias son solo de nueve a 15 nucleótidos (sustancias que componen el ADN y ARN del virus). (RODRÍGUEZ, 31 de marzo, 2015)

Para el gran público, la diferencia en nucleótidos no es comprensible, aunque se les conceptualice entre paréntesis (frase que no ayuda mucho a entender tampoco).

Los científicos son mencionados como grupo en La Nación, de forma anónima al igual que en el periódico mexicano. En este punto se advierte otra diferencia con El País, pues el diario español no incorpora a científicos ni hace descripciones del virus con base en ciencia, sino que se enfoca en el drama humano y logra reflejar el comportamiento de la epidemia con esta narrativa.

Por último, en una parte del texto en La Nación se utiliza una publicación en calidad de vocero, cuando se afirma "el reporte concluyó" o "resaltó la publicación que", lo cual personifica un reporte o estudio. Esta personificación llega a sustituir al personal científico responsable de los descubrimientos y de esa publicación, con lo cual invisibiliza a los autores.

\section{Análisis narrativo}

Este análisis se basa en la secuencia narrativa del relato desde su situación inicial hasta su final.

La Nación: en la narrativa de La Nación, el eje central es la descripción de un descubrimiento publicado en la revista Science: la mutación lenta del ébola que permitiría desarrollar una vacuna. Como el formato de este reportaje es de unión de notas (noticia múltiple), este reportaje tiene una situación inicial adicional que aborda las diferencias en tiempo de incubación, síntomas y mortalidad que causa la edad del enfermo de ébola, que se fundamenta en un estudio publicado en una revista diferente a la que sustenta el titular principal. La noticia principal exhibe un párrafo de inicio que dice:

El virus del Ébola, causante de la epidemia del año pasado en África y que aún no ha podido ser erradicado en ese continente, cambia su composición genética (mutación) de forma más lenta que la sospechada en un inicio por los científicos. (RODRÍGUEZ, 2015) 
El texto anterior corresponde al formato de pirámide invertida en las noticias de narrativa tradicional. López (1997), citando a Clark, comparte que "a pesar de su preeminencia, la pirámide invertida tiene importantes debilidades como forma de comunicación. Algunos reporteros piensan que es un camino antinatural para contar la historia (story)". (p. 18) Esta fórmula de pirámide es más expositiva y los lectores no la asocian con una historia o relato entretenido, sino que se informan entre el titular y el primer párrafo con lo que, en no pocas ocasiones, no terminan de leer.

Al inicio de un relato, los protagonistas deberían quedar presentados, dejando que el lector conozca al sujeto, sus características predominantes y la acción principal que realiza. En este caso el reportaje carece de contexto pues no se aclara qué es el ébola, cómo se contagia y sus números acumulados a la fecha, por ejemplo.

El texto en La Nación carece entonces de cronología y de un devenir de relato y es meramente informativo. No existe un nudo, transformación o complicación de los eventos ni de los protagonistas, ni tampoco una acción que corresponda a la situación inicial, y mucho menos una evaluación de la misma.

Como final del texto, la autora advierte que pasarán muchos años antes de poder probar la efectividad de una vacuna preventiva para ébola, y hace suyas las palabras del reporte de la OMS advirtiendo que los niños pequeños ocupan más seguimiento y mayores investigaciones científicas para atenderlos.

El Universal: en este diario no se puede realizar el análisis narrativo en función de una historia dado que el texto dedicado al ébola fue corto dentro del gran reportaje de enfermedades incurables.

La introducción hace un listado de las enfermedades que serán abordadas destacando la gravedad de la epidemia más reciente del ébola en África occidental y luego continua con la descripción de síntomas y de formas de contagio para terminar manifestando que no hay tratamiento específico para ella.

Como se observa, este es un claro ejemplo del modelo de déficit en comunicación pública de la ciencia, pues informa directamente sobre peligro y prevención sin esfuerzos narrativos complejos que permitan al usuario crear una imagen más cercana del suceso de interés. No hay nudos, complicaciones o evolución de personajes que se puedan analizar.

El País: el autor español del reportaje sobre ébola enlaza varias historias, y cada una es un micro relato en sí misma, pero al avanzar cronológica y geográficamente al narrarlas, brinda un mirada al lector sobre el comportamiento de la epidemia en su paso por Guinea, Sierra Leona, Liberia y Nigeria, a través de los ojos de testigos desconocidos pero con los cuales la audiencia se puede identificar.

La situación inicial traslada al lector a Guinea, donde en marzo del 2014 las autoridades de ese país anuncian que el ébola ha llegado a la capital. En ese mismo párrafo se colocan los datos de casos y muertos que en un año ha causado el virus e inmediatamente 
dan la frecuencia de contagios actuales por semana, advirtiendo que se ha "ralentizado" pero que sigue activo. El párrafo empieza en tiempo pasado y termina en presente, dando pie al recorrido de casos que son centrales en el reportaje y que ayudan a retratar la crisis vivida de marzo a diciembre del 2014.

\footnotetext{
A lo largo de estos doce meses alumbró historias de muerte y estigma, pero también de superación y solidaridad. Estas son algunas de ellas. (NARANJO, 22 de marzo, 2015)
}

El autor hace la transición anterior al final del primer párrafo del reportaje, con lo cual se hace cercano al lector y le dice que lo que viene es una narrativa diferente. En este punto inician los microrrelatos alrededor de los contagios, en los que se identifican composiciones individuales que se analizarán una a una.

- Mamadou Cissé, Guinea: usan un nombre ficticio para este primer contagio. La acción inicia el 14 de marzo del 2014 en la capital de Guinea. Mamadou recibe a su hermano que llega de visita ya con síntomas de la enfermedad. La complicación llega cuando él muere cuatro días más tarde, cuando todavía no sabían el porqué. La consecuencia: pocos días después seis miembros de esa familia y una parte del personal sanitario se habían enfermado. Como situación final, aunque Mamadou y su esposa se salvaron, sus vecinos cerraban puertas y ventanas a su paso.

Los hechos mencionados cumplen con la narrativa básica del cuento. Hay una situación de partida que se complica y a partir de la cual hay consecuencias que afectan al protagonista y su contexto, que llegan a una resolución, que en este caso es favorable porque salva su vida, pero que es agridulce cuando en la situación final se describe el rechazo de los vecinos, que sienten temor ante posibilidades de contagio. La transición hacia el segundo relato se aprovecha para mencionar que, para ese momento, el virus ya tenía tres meses circulando y que la causa podría ser un murciélago, citando una investigación publicada en la revista científica que brinda una fuente experta dentro del texto. Se añade que los entierros surgen como focos de contagio: este último dato es el pie perfecto para el inicio del siguiente relato y, a la vez, se convierte en información educativa.

- Doctor Umar Khan, Sierra Leona: una vecina de un pueblo en Sierra Leona va a un entierro en Guinea y a su regreso lleva el virus a su país. En un hospital regional en Sierra Leona, los enfermos se multiplican y el lugar se convierte en foco de contagio. Umar Khan, doctor que luchó contra la enfermedad en el hospital, muere a causa de ella.

La estructura también se observa definida con respecto a cómo inicia, la complicación que causa un nudo en el relato, las consecuencias y la resolución para el protagonista. El punto final, que trata de atenuar esa muerte, es decir que Sierra Leona considera al doctor un héroe.

La transición hacia el tercer relato, es una comparación que hace el periodista 
diciendo que Sierra Leona tenía el brote limitado a dos pueblos mientras que en Liberia el ébola mataba en la capital.

- Religioso español Miguel Pajares: el 1 de agosto del 2014, Miguel Pajares de 75 años, esperaba resultados en el hospital en Liberia, mientras pedía auxilio a su país al sentirse enfermo. Al confirmarse la enfermedad, el gobierno español lo repatrió a Madrid el 7 de agosto, pero murió el 12 convirtiéndose en la primera víctima mortal en Europa.

Este caso le brinda más proximidad al lector español, haciendo más tangible el peligro y dándole esa dimensión mundial a la epidemia. El relato cambia un poco con respecto a los anteriores, pues no es cronológico. La situación inicial es del protagonista sufriendo los síntomas y comunicándose con su país, en un recurso emocional que levanta el relato, cuando ya va a mitad de camino. A continuación, el texto regresa en el tiempo para explicar cómo se contagió: cuidó del director del hospital hasta que este murió y por esa causa las autoridades cerraron el hospital y allí estaba cuando comunicó su situación a su país. La resolución y situación final es similar a la anterior, cuando da la fecha de muerte.

El párrafo de transición empieza con una personificación atribuida a un país: "Mientras Liberia se asoma al abismo con barrio enteros encerrados", que trata de expresar que el problema es grave y extendido; que es nacional. Esta frase también constituye una metáfora, donde la epidemia coloca al país en un peligro tal que puede caer y no retornar. Este tipo de recursos corresponden al género más interpretativo que usó el autor.

- Patrick Sawyer, asesor del Gobierno liberiano: se inicia informando que el virus ha saltado a Nigeria, el país más poblado del continente y eso es en realidad la situación final de este microrrelato, dado desde el principio. A partir de allí el relato se devuelve en el tiempo, contando que Patrick Sawyer decidió viajar el 20 de julio a Nigeria luego de que su hermana murió por ébola, pero ya en el avión tenía síntomas fuertes. La persona que lo recogió en el aeropuerto lo llevó de inmediato al hospital pero murió cuatro días después (resolución), dejando a ese compañero contagiado junto a personal sanitario, y causando suspensión de vuelos en Guinea, Sierra Leona y Liberia. La situación final de este relato cuenta cómo la rápida reacción de autoridades controló el brote, pero no impidió que Senegal y Malí registraran casos dada la movilidad por carretera.

- Otros enfermos: Manuel García, otro religioso español, fue trasladado desde Sierra Leona a España en setiembre y murió en el hospital. Teresa Romero, auxiliar de enfermería, quedó contagiada, siendo el primer caso de transmisión fuera de África. En esta parte del relato ya se pierden las historias y se va preparando el final, diciendo que la ayuda internacional y el cambio de hábitos de la población mediante la comprensión de la enfermedad dieron resultado para diciembre, cuando se disminuyeron los contagios a un centenar a la semana. 
El dato anterior cierra el penúltimo párrafo del reportaje y da paso al texto de cierre, que se elabora en tiempo presente, informando de un caso nuevo en Liberia justo cuando ese país iba a ser declarado libre del virus. También en Guinea se registraron tres médicos infectados en un entierro no seguro. Estos ejemplos son para ilustrar que los contagios continúan, con lo cual la amenaza global también.

Con respecto a los actores sociales, el texto de El País es el único que los contempla. Las citas indirectas son sobre 6 enfermos, mientras que las declaraciones son de 3; del primer enfermo en la capital de Guinea son dos citas: "Cierran las puertas y las ventanas a nuestro paso"; y "tienen miedo, nos rechazan, nos señalan con el dedo". La otra declaración es del primer muerto de ébola en Europa que narraba: "Me siento enfermo, estoy esperando a que me hagan la prueba, no quiero contagiar a nadie". Estas citas colocan a estos actores en posiciones vulnerables, pasivos y en estado depresivo. Uno sobrevivió y el otro murió. Ambos varones.

Ni en La Nación ni en El Universal hay apertura del texto a actores sociales, por ende, no hay testimonios $u$ opiniones de enfermos, sus familias $u$ otros ciudadanos. Esta decisión en el uso de fuentes tiene que ver con la razón de ser de los reportajes: en La Nación se informa de un descubrimiento; en El Universal se describe al ébola como enfermedad incurable, como un recordatorio informativo; y en El País se cuenta el drama humano mediante una cronología de casos seleccionados, que abarcan casi un año.

Como se demuestra con este análisis, los relatos del diario español retratan la enfermedad y la emergencia vivida con el ébola en el 2014, por medio de una narrativa donde se incorporan elementos presentes en textos literarios y que cautiva al lector al componer algunos rostros de la tragedia. Tanto el tratamiento, como la estructura y estilo son muy diferentes a los textos de La Nación y El Universal.

\section{Recursos literarios}

Este estudio parte de que la narrativa periodística más interpretativa, con mayores recursos literarios y extensión, puede incidir mucho más en los lectores y mejorar así su cultura científica. Es por esta razón, que estos recursos se abordan en esta sección, mediante la síntesis que contiene la tabla 4.

En la categoría de figura literaria se evidencia que el reportero en El País utilizó este recurso de forma más amplia que los otros dos periódicos. La tabla siguiente contiene ejemplos de metáforas, personificación y exageración, todas para reforzar el pánico, la incertidumbre y la capacidad de contagio del virus. También utilizan gran cantidad de enlace situacionales que dan al lector la ubicación en el tiempo en un reportaje retrospectivo: una semana más tarde, en el mes de julio, pocos días después y otros.

La Nación solo incluyó una oración, a través de las declaraciones de un experto, en la 
que compara la lenta mutación del ébola con la estabilidad de la gripe aviar. Su texto al ser informativo y en pirámide invertida, centra su relato en el resultado de un estudio científico, destacando la actualidad y el aporte. El Universal, también como texto informativo y más corto, no ofrece ninguna figura literaria.

En construcción de imágenes a través de la descripción, cada periódico tuvo solo un indicio en esta línea (ver la tabla 4) y se relacionan los tres con la seguridad de los pueblos y capitales donde hay enfermos, mediante encierros y bloqueos de seguridad y contención. La descripción del contexto, del ambiente o de la infraestructura, son elementos que no son abordados, como tampoco las características físicas de las personas. Lo que sí logra el texto de El País integralmente es transmitir la impotencia, el pánico y la incertidumbre sin fin en la región y para ello agrega adjetivación a su texto, con palabras como misteriosas, activa, inesperada, insuficiente, inquietante, interminables, diferente, desesperado y meticuloso.

Tabla 4 - Recursos literarios en los reportajes sobre ébola en los diarios analizados

\begin{tabular}{|c|c|c|c|}
\hline Diario & El País & El Universal & La Nación \\
\hline $\begin{array}{l}\text { Figuras } \\
\text { literarias }\end{array}$ & $\begin{array}{l}\text { "La noticia cayó como una bomba" } \\
\text { "El estigma les persiguió" } \\
\text { "Mientras Liberia se asomaba al } \\
\text { abismo" } \\
\text { "La tarea de contención fuera titánica" } \\
\text { La enfermedad de colaba en una gran } \\
\text { ciudad } \\
\text { "Los pacientes llegaban desde todos } \\
\text { los rincones" } \\
\text { "Y Khan lo pagó con su vida" }\end{array}$ & -- & $\begin{array}{l}\text { Comparación del virus de ébola } \\
\text { con el de influenza aviaria. "El } \\
\text { virus de influenza aviaria lleva } \\
\text { más de } 20 \text { años } \\
\text { transmitiéndose en millones de } \\
\text { aves y aún no ha logrado mutar } \\
\text { y transmitirse de forma } \\
\text { sostenida de persona a } \\
\text { persona" }\end{array}$ \\
\hline $\begin{array}{l}\text { Construcción } \\
\text { de imágenes }\end{array}$ & $\begin{array}{l}\text { "Con barrios enteros encerrados en } \\
\text { cuarentena y centros de tratamiento } \\
\text { desbordados" }\end{array}$ & $\begin{array}{l}\text { La imagen del } \\
\text { enfermo de } \\
\text { ébola mediante } \\
\text { sus síntomas } \\
\end{array}$ & "Crear un anillo de seguridad" \\
\hline Preguntas & -- & -- & $\begin{array}{l}\text { Se deja una incógnita hacia el } \\
\text { final del texto. "Aunque el } \\
\text { rango de edad con menos } \\
\text { contagios es el de menores de } \\
\text { cinco años, también es el } \\
\text { periodo en el que esta } \\
\text { enfermedad se comporta de } \\
\text { manera más agresiva. Empero, } \\
\text { los investigadores desconocen } \\
\text { las razones exactas de este } \\
\text { comportamiento" }\end{array}$ \\
\hline Emociones & $\begin{array}{l}\text { Tienen miedo } \\
\text { "Me siento enfermo" } \\
\text { En un intento desesperado por } \\
\text { salvarse }\end{array}$ & $\begin{array}{l}\text { México } \\
\text { vulnerable a } \\
\text { sufrir epidemias } \\
\text { parecidas al } \\
\text { ébola }\end{array}$ & $\begin{array}{l}\text { Agresivo } \\
\text { La iniciativa da esperanza } \\
\text { Preocupación }\end{array}$ \\
\hline $\begin{array}{l}\text { Sorpresa y } \\
\text { humor }\end{array}$ & Sorpresa: "inesperada visita” & -- & -- \\
\hline
\end{tabular}

Fuente: elaboración propia a partir de reportajes del I semestre 2015 
En cuanto al recurso retórico de preguntas, este no fue utilizado como tal, y solamente La Nación deja una incógnita a sus lectores, cuando mencionan que los investigadores desconocen las razones por la cuales los niños menores de cinco años se contagian menos, dando una mirada prospectiva sobre líneas de investigación pendientes.

En síntesis, aunque el ébola fue de interés para los tres periódicos en estudio en el mismo periodo, todos lo abordaron desde diferentes hechos noticiosos y tratamiento, con dos inactuales y uno actual, dos informativos y uno interpretativo, y con estructuras diversas: uno esquemático, uno múltiple y uno cronológico. Los reportajes responden a un interés globalizado, pues la epidemia en África supone un peligro mundial por la movilización de personas, por el desconocimiento de la población y por lo poco que se puede hacer una vez que hay contagio.

\section{Conclusiones}

La cobertura de esta enfermedad por los tres periódicos comprueba la importancia mundial de la epidemia del ébola y el impacto que los temas de salud pública tienen en los medios de comunicación.

Los medios de comunicación tienen el deber de informar sin poner en peligro la salud pública o la buena marcha de las actuaciones que se estén llevando a cabo para la gestión y control de la epidemia. (FUNDACIÓ VILA CASAS, 2014, p. 40)

En relación con los reportajes, todos los artículos incluyeron a la Organización Mundial de la Salud (OMS) como fuente de información, lo que demuestra que es reconocida en ámbito mundial y produce informes en los que los Gobiernos y comunidad científica confían. La revista New England Journal of Medicine es revisada por los periodistas científicos para su trabajo en salud; y que se destacan las fuentes organizacionales consultadas, por sobre las o los expertos.

Los actores de la sociedad civil, concebidos como víctimas, fueron los que tuvieron el peso de la narración en el diario El País, incluso con declaraciones atribuidas. En adición, los personajes tienen poca descripción de sus características (físicas o emocionales) y sus actos son más importantes. Las fuentes nacionales expertas no fueron un recurso de apoyo clave para ninguno de los periódicos.

La tendencia de la cobertura en El País fue darles voz a los enfermos de ébola y a algunos de los que murieron, pero las mujeres, una de las principales víctimas, no fueron consideradas. Las autoridades, un protagonista bastante disminuido, son incluidas de forma anónima, como un colectivo, y en labores operativas de atención de la emergencia, sin 
emociones ni cercanía con los enfermos.

En El Universal, tanto los enfermos como los especialistas fueron colectivos anónimos, pero solo los segundos tuvieron voz. La Nación, por su parte, también coloca al ébola como protagonista clave y no a los enfermos, ni el ambiente en el que se desarrollan las tragedias, como sí lo hizo el periódico español.

Existen oportunidades de mejora en la cobertura de historias en ciencia y salud: se deben equilibrar las fuentes en cuanto a su género, con el fin de visualizar a las mujeres como expertas en sus áreas; hay noticias de relevancia mundial que no obtienen reportajes extensos ni se les da prioridad en todos los periódicos; y no siempre hay apoyo desde los medios para que el reportero en salud desarrolle reportajes extensos. Aunque se vislumbran cambios en la narrativa, especialmente en El País, todavía hace falta la interpretación y las historias que den voz a los actores sociales.

La sociedad necesita la ciencia. Antonio Calvo Roy lo afirma de manera categórica en una columna de opinión publicada en el diario El País, el 9 de junio del 2017:

\begin{abstract}
En este mundo en el que la ciencia y la tecnología juegan un papel cada día más importante, es fundamental que la sociedad tenga los conocimientos y las palabras para poder formarse opinión -y ojalá criterio- en torno a ellos. Del cambio climático a la energía solar, de los transgénicos a la robótica, de la sexta extinción y sus consecuencias al uso de células madre, los ciudadanos han de opinar $y$, sobre todo, han de obligar a los gobernantes a tomar decisiones correctas. Pero, para eso, han de tener opinión fundada de las cuestiones, para lo que resulta básico, una información fiable, contrastada, rigurosa. No mentiras ni hechos falsos, información rigurosa. (párr. 5)
\end{abstract}

Impulsar narrativas innovadoras es uno de los caminos en que el periodismo científico puede reinventarse para hacerse leer y oír de su audiencia y usuarios. La apertura del texto a personas de la sociedad civil, no expertos, es una de las formas para volver el contenido más cercano. Vincular el descubrimiento publicado en una revista científica con el diario vivir de un ciudadano genera interés y es más probable que sea recordado (MENAYOUNG, 2017).

Los periodistas deben ser más cercanos con las comunidades, sus necesidades y sus impactos, observar y escuchar, para poder elaborar contenidos que no solamente informen, sino que puedan contar historias, formen y den cohesión en los temas claves que atañen directamente a la calidad de vida de la sociedad.

\title{
Referencias
}

ALCIBAR, M. Human Cloning and the Raelians Media Coverage and the Rhetoric of Science. Science Communication, v. 30, n. 2, p. 236-265, 2008. 


\section{https://doi.org/10.1177/1075547008324429}

ALEXA.COM. Traffic Statistics. Disponible en http://www.alexa.com. 2016.

ALLEPUZ-FAUS, A.; CARO, I.; ROJO-SERRANO, I.; YERA-SABATER, A. La asimilación de experiencias problemáticas a través de narraciones: un estudio de caso. Anales de psicología, v. 30, n. 1, p. 56-69, 2014. https://doi.org/10.6018/analesps.30.1.153991

BERRUECOS, L. La narración en un artículo de divulgación científica. Anuarios de investigación $\mathrm{n}$. 1 , p. 617-640, 2005. Recuperado de http://148.206.107.15/biblioteca_digital/capitulos/38-1377moh.pdf.

BRAUN, J. A. The Imperatives of Narrative: Health Interest Groups and Morality in Network News. The American Journal of Bioethics, v. 7, n. 8, p. 6-14, 2007. https://doi.org/10.1080/15265160701462244

BRECHMAN, J.; LEE, C.; CAPPELLA, J. N. Lost in Translation? A Comparison of Cancer-Genetics Reporting in the Press Release and Its Subsequent Coverage in the Press. Science Communication, v. 30, n. 4, p. 453-474, 2009. https://doi.org/10.1177/1075547009332649

CALVO, A. Periodismo de ciencia, periodismo enrabietado. El País, España. Recuperado de http://elpais.com/elpais/2017/06/08/ciencia/1496933982_127392.html?id_externo_rsoc=F

B_CC. 9 de junio del 2017.

COKKINIDES, V.; KIRKLAND, D.; ANDREWS, K.; SULLIVAN, K.; LICHTENFELD, J. L. A profile of skin cancer prevention media coverage in 2009. Journal of The American Academy of Dermatology, v. 67, n. 4, p. 570-575, 2012. https://doi.org/10.1016/i.jaad.2011.11.920

CONNOLLY-AHERN, C.; BROADWAY, S. C. "To booze or not to booze?" Newspaper coverage of fetal alcohol spectrum disorders. Science Communication, v. 29, n. 3, p. 362-385, 2008. https://doi.org/10.1177/1075547007313031

D'ANGELO, P.; POLLOCK, J.C.; KIERNICKI, K.; SHAW, D. Framing of AIDS in Africa. Politics \& the Life Sciences, v. 32, n. 1, p. 100-125, 2013. https://doi.org/10.2990/32 2100

DIXON, G., CLARKE, C. E. Heightening Uncertainty Around Certain Science: Media Coverage, False Balance, and the Autism-Vaccine Controversy. Science Communication, v. 35, n. 3, p. 358-382, 2013. https://doi.org/10.1177/1075547012458290

ECHEVARRÍA, B. El reportaje periodístico: una radiografía de la realidad. Comunicación Social Ediciones y Publicaciones: Zamora, España, 2011.

EVENSEN, D. T.; CLARKE, C. E. Efficacy Information in Media Coverage of Infectious Disease Risks: An III Predicament? Science Communication, v. 34, n. 3, p. 392-418, 2012. https://doi.org/10.1177/1075547011421020

FECYT. Percepción social de la ciencia y la tecnología en España. Madrid: Fundación Española para la Ciencia y la Tecnología, 2018. Recuperado de https://icono.fecyt.es/informes-ypublicaciones/percepcion-social-de-la-ciencia-y-la-tecnologia-en-espana.

FUNDACIÓ VILA CASAS. La comunicación pública sobre la enfermedad del Ébola. Informe Quital. Barcelona: Universitat Pompeu Fabra, 2014. Recuperado de http://ccs.upf.edu/wpcontent/uploads/InformeQuiral2014.pdf.

HOGAN, C. Ebola striking women more frequently than men. The Washington Post, 2014. Recuperado de https://www.washingtonpost.com/national/health- 
science/2014/08/14/3e08d0c8-2312-11e4-8593-

da634b334390_story.html?utm_term=.6e2d88fbcc04. 14 de agosto, 2014.

KREUTER, M.; GREEN, M.; CAPPELLA, J.; SLATER, M.; WISE, M.; STOREY, D.; CLARK, E. et al. Narrative Communication in Cancer Prevention and Control: A Framework to Guide Research and Application. The Society of Behavioral Medicine, v. 33, n. 3, p. 221-235, 2007. https://doi.org/10.1007/BF02879904

LÓPEZ, F. Consideraciones sobre la narratividad de la noticia. El imperio de una sinécdoque. Comunicación y sociedad, v. 10, n. 1, p. 9-60, 1997.

MENA-YOUNG, M. La memoria y la lectura de reportajes de ciencia: medición de la recuperación de información. Revista Question, v. 1, n. 53, p. 301-320, 2017.

MENÉNDEZ, C. Ser mujer en el epicentro del ébola. El Mundo. Recuperado de http://www.elmundo.es/salud/2015/03/08/54f9ca25e2704ec6458b457b.html. 8 de marzo, 2015.

NARANJO, J. El ébola se enroca. El País. Recuperado de http://internacional.elpais.com/internacional/2015/03/22/actualidad/1427030515_601641. html. 2015.

NEGReTE, A. La Comunicación de la Ciencia a través de medios culturales narrativos: métodos cuantitativos y cualitativos para su evaluación. Revista Latinoamericana $e$ Comunicación Chasqui, n. 119, p. 43-53, 2012.

NERLICH, B.; KOTEYKO, N.; BROWN, B. Theory and language of climate change communication. Wiley Interdisciplinary Reviews-Climate Change, v. 1, n. 1, p. 97-110, 2010. https://doi.org/10.1002/wcc.2

NISBET, M.; MARKOWITZ, E. Understanding Public Opinion in Debates over Biomedical Research: Looking beyond Political Partisanship to Focus on Beliefs about Science and Society. PLOS ONE, v. 9, n. 2, p. e88473, 2014. https://doi.org/10.1371/journal.pone.0088473

PALAU D. Inscripción en cuatro movimientos. Estilos en la construcción del texto informativo -interpretativo. Comunicación y Sociedad. n. 21, p. 213-238, 2014. Recuperado de http://www.comunicacionysociedad.cucsh.udg.mx/sites/default/files/a8_23.pdf.

PARDO, P. El ébola puede convertirse en 'una pandemia como el sida'. El Mundo. Recuperado de http://www.elmundo.es/salud/2014/10/10/5437b3fb268e3ee80a8b4575.html. 10 de octubre, 2014.

RACINE, E.; BAR-ILAN, O.; ILLES, J. Brain imaging - A decade of coverage in the print media. Science Communication, v. 28, n. 1, p. 122-143, 2006. https://doi.org/10.1177/1075547006291990

RAMONET, I. La Explosión del Periodismo. Madrid: Clave Intelectual, S.L., 2011.

REIG, R. Crisis del sistema, crisis del periodismo. Contexto cultural y deseos de cambio. Barcelona: Editorial Gedisa, 2015.

REN, J.; PETERS, H. P.; ALLGAIER, J.; LO, Y. Similar challenges but different responses: Media coverage of measles vaccination in the UK and China. Public Understanding of Science, v. 23, n. 4, p. 366-375, 2014. https://doi.org/10.1177/0963662512445012

RODRÍGUEZ, I. Virus del Ébola muta más lento de lo sospechado. La Nación. Recuperado de 
https://www.nacion.com/ciencia/salud/virus-del-ebola-muta-mas-lento-de-losospechado/MLHRRWMJ7ZDRRPNTBZO3ULPLQI/story/. 31 de marzo, 2015.

SOLÁ, S. Hacia una tipología de narrativas mediáticas identitarias. Revista Sphera Pública, v. 13, n. 2, p. 30-48, 2013.

UNGAR, S. Global bird flu communication - Hot crisis and media reassurance. Science Communication, v. 29, n. 4, p. 472-497, 2008. https://doi.org/10.1177/1075547008316219

VICSEK, L. Costs and Benefits of Stem Cell Research and Treatment: Media Presentation and Audience Understanding in Hungary. Science Communication, v. 33, n. 3, p. 309-340, 2011. https://doi.org/10.1177/1075547010389820

ZHAO, F.; CHEN, Y.; GE, S.; YU, X.; SHAO, S.; BLACK, M.; WANG, Y.; ZHANG, J.; SONG, M.; WANG, W. A Quantitative Analysis of the Mass Media Coverage of Genomics Medicine in China: A Call for Science Journalism in the Developing World. OMICS-A Journal of Integrative Biology, v. 18, n. 4, p. 222-230, 2014. https://doi.org/10.1089/omi.2013.0108

Recebido em: 09/10/2019. Aceito em: 19/02/2020. 